Submission to Energy and Buildings special issue on occupancy behavior

\title{
Using Synthetic Population Data for Prospective Modeling of Occupant Behavior during Design
}

Clinton. J. Andrews*, MaryAnn Sorensen Allacci, Jennifer Senick, Handi Chandra Putra, and Ioanna Tsoulou; Center for Green Building, Edward J. Bloustein School of Planning and Public Policy, Rutgers University, New Brunswick, NJ, USA

* Corresponding author, CJA1@RUTGERS.EDU

Abstract

This paper addresses the challenge of incorporating occupant behavior into building performance simulation models used during the design process - that is, before the actual occupants are known. It proposes the use of synthetic population data, an approach that is novel in building performance modeling although common in urban planning and public health. A simpler approach embodied in the ASHRAE Fundamentals volume is to report standard distributions of values for behavioral variables, assuming that parameters vary independently of one another when in fact many co-vary or are interdependent. An alternative approach calibrates models of occupant behavior against actual occupants in specific existing buildings, but this raises questions of transferability. Needed is a database of "generic" occupants that designers can use prospectively during the design process. This paper documents a process of combining disparate field studies of commercial buildings into a larger occupant behavior database and generating a statistically similar synthetic data set that can be shared without compromising confidentiality requirements associated with field studies. The synthetic data set successfully incorporates much of the covariance structure of the underlying field data and supports multivariate modeling. Its scope and structure necessarily serve the needs of the associated modeling framework. Cooperative and systematic sharing of data by field researchers is crucial for building large enough data sets to serve as a behaviorally-robust basis for building design. 
Keywords: occupant behavior, energy, simulation, synthetic data

Acknowledgements: The authors have benefitted from participating in the IEA-EBC Annex 66 expert working group on Definition and Simulation of Occupant Behavior in Buildings. Funding was provided by the Consortium for Building Energy Innovation (CBEI) sponsored by the U.S. Department of Energy under Award Number DE-EE0004261.

\subsection{Introduction}

Design choices directly determine many aspects of building performance, but occupant responses to comfort conditions they experience can also influence energy performance [1]. Occupants can adjust thermostats, open windows, or install fans or heaters, and building operators may monitor occupant concerns and dynamically respond to their behaviors and preferences [2-4]. Hence there is value in understanding potential occupant influences early in the design process, before occupancy actually occurs.

Building performance modelers by necessity often ignore aspects of occupant behavior by assuming fixed comfort targets and ignoring "unregulated" energy loads. This is the standard practice even though researchers have shown that occupants influence building performance by their choice of setpoints, schedules, and adaptive behaviors, many of which are heterogeneous, often habitual, and sometimes maladaptive $[5,6]$. Parsimonious, accurate and reliable representations of expected adaptive behaviors that respond to comfort conditions experienced in new buildings have not been available to most practitioners [7]. This paper presents one way to bring insights from occupant behavior research to the building design process that strives to balance parsimony and accuracy.

Data collected about occupant behavior inevitably comes from existing buildings and experimental setups, whereas designers must build new buildings whose occupants are not yet known. Some behavior is context-dependent, so there is a need to study how transferable the knowledge gained from retrospective study of occupant behavior is to new building contexts. This paper identifies four broad transfer approaches discussed in greater detail next: (1) develop standard distributions for design 
guidance; (2) calibrate building performance models against existing occupied buildings, then apply the calibrated building performance model elsewhere; (3) calibrate separate occupant behavior and building performance models in co-simulation against an existing building, then apply the calibrated occupant behavior model elsewhere; and (4) develop a representative occupant behavior data set for use in cosimulations that link occupant behavior and building performance models.

\subsection{Develop standard distributions}

Large data sets incorporating thousands of occupants in hundreds of buildings underlie standard distributions of thermal comfort preferences summarized in the ASHRAE Fundamentals volume [8] and adopted in ASHRAE Standard 55 [9] and the associated primary literature, e.g., [10]. Occupants' predicted mean votes (PMV) on the ASHRAE 7-point thermal comfort scale, which ranges from cold (-3) to hot (3), depend strongly on their metabolic rate and clothing type, plus ambient air temperature, mean radiant temperature, air velocity, and relative humidity. PMV, in turn, drives the predicted percentage of dissatisfied occupants (PPD). ASHRAE Standard 55 [9] focuses its guidance on the central tendency in this distribution, recommending that designers seek to satisfy the $90 \%$ of occupants whose PMV lies between -0.5 and +0.5 on the thermal comfort scale. Designers may assume fixed indoor air temperature targets for use in subsequent analysis and equipment sizing calculations.

Complicating contextual factors may cause the standard thermal comfort distribution to shift between summer and winter, and between buildings with mechanical and natural ventilation [11]. Indeed, "because of the large interpersonal variability in thermal requirements, some occupants in any uniformly conditioned environment will be too warm at the same time as others are too cool" [8]. A comparison of the 1989 and 2013 versions of the ASHRAE Fundamentals thermal comfort chapter shows that the older guidance focused on the central tendency in the distribution of occupant perceptions and responses, but the more recent version focuses also on the distribution of perceptions and behaviors 
around that central tendency, which opens up new design possibilities such as for personal environmental control systems $[8,12]$. On this basis, designers may assume a distribution of desired indoor air temperatures when performing analysis and selecting equipment.

The standard distribution approach is transferable in the sense that it has been disseminated by ASHRAE [8] and is easy to use. However, it fails to capture the dynamic effects of feedbacks including adaptive responses by occupants to changing building conditions. Simulation modeling is necessary to add the dynamics.

\subsection{Calibrating models using occupied buildings}

Most building performance models simulate a dynamic system using deterministic equations driven by time-varying physical and behavioral parameters [13]. In an extension of the standard distribution approach discussed previously, guidance manuals such as ANSI/ASHRAE/IES Standard 90.1 Appendix G [14] specify typical occupancy schedules, diversity factors and other standardized behavioral assumptions to include in simulations of new buildings. However, modelers find that the resulting simulations may not match reality when calibrated against existing buildings [15].

Standardized calibration approaches have therefore emerged, with most relying on manual, iterative adjustments of parameters for a few key variables [16]. A growing literature recommends setting goodness-of-fit criteria in advance, gathering detailed data over time and by zone, seeking independent measurement of weather-related and internal loads, tuning weather-dependent variables first, and expecting more experienced modelers to fare better than those with less experience [17-22]. A complementary literature recommends statistical strategies for managing this underdetermined optimization problem by using systematic searches or heuristic strategies to identify the most influential variables, using penalty functions to reduce overall error, and taking spot measurements to reduce key uncertainties $[23,24,16]$. A consistent finding is that statistical noise due to occupancy patterns and 
occupant behavior limits the accuracy of calibration efforts $[25,26]$. Most of these factors limit the transferability of calibrated models from existing to future buildings. Instead, it seems that the experience of the modeler is the most transferable element.

\subsection{Co-simulating occupant behavior \& building performance}

Social and behavioral scientists have a long tradition of modeling human behavior $[27,28]$, and computer scientists have developed a parallel tradition relying on a procedural rather than correlative framing of behaviors, e.g., [29-31]. Recently a new class of building energy performance simulation models focusing on occupant behavior has emerged that favors probabilistic, Markov process, and agent-based modeling approaches to represent interactions between building systems and occupants, e.g., [32-35]. Of particular interest are models that co-simulate occupant behavior and building performance by dynamically coupling behavioral models with standard design tools such as EnergyPlus using interface ontologies such as obXML $[36,37]$.

Calibration of a coupled occupant behavior and building performance modeling system is an elaborate and interactive process that involves collecting the usual detailed data on building geometry and energy consumption at both the component and building-wide levels, as well as detailed data on occupancy patterns, occupant sensations and perceptions, and their adaptive responses to conditions in the building [38]. As was the case with building performance models discussed previously, calibration efforts are typically manual, iterative and rely on heuristics and the modeler's expertise. The constraining factor is usually the limited amount of occupant behavior data that is available, even for a well-funded study of an existing building.

While detailed models of this type hold interest for researchers, not all have practical value, and often a more parsimonious, fit-for-purpose approach is warranted [7]. One parsimonious strategy is to present practitioners with a generic and hopefully representative occupant data set for use in modeling. 


\subsection{Representative occupant population}

Most research in the occupant behavior domain involves small data sets. Some researchers pursue longitudinal studies of a small number of occupants, e.g., [36], others do cross-sectional studies of a larger number of occupants, e.g., [39]. The typical calibration approach combines top-down and bottomup elements by codifying a theory of human behavior in equations and fitting the parameters of those equations. One approach, reflecting the current state of data, is to focus on the distribution of values for each modeling parameter separately, that is, assuming independent bivariate functional relationships. This allows the modeler to borrow parameters and standard distributions from others to apply in the model when local data are not available. The modeling framework then needs to incorporate logic showing how these functional relationships interact to yield multivariate covariance, as is shown in [36]. A second approach, which the current paper advances, is to focus even more ambitiously on a representative population of occupants in order to capture interactions and covariation within a defined set of contextual parameters. Such a data set would be particularly helpful for calibrating agent-based models of occupant behavior but it should also be useful in other modeling traditions.

It is easier to imagine a representative population of building occupants than to find one that is well documented. There are many potential variables of interest, such as age, gender, schedule (daily, weekly, seasonal), metabolism, clothing, multiple adaptive behaviors, and comfort perceptions, and many measured values are context-dependent [40]. Currently, there is much data on thermal comfort and less on lighting, adaptive responses, and social aspects of behavior. In the long run, "big" behavioral data from smart buildings with ubiquitous sensors and interactive features will emerge. In the meantime, it is necessary to aggregate many small data sets together to provide an adequate foundation for the desired representative population of building occupants. 
This paper illustrates that process by aggregating three disparate data sets, exploring the properties of each separately and in aggregate, and anonymizing the data by creating a synthetic population with covariance characteristics that are similar to the underlying data set. Given occupants' privacy concerns, an important benefit of creating a synthetic population is to preserve anonymity in data sets that could become widely used in practice [41]. Its focus is commercial buildings.

Procedures for developing synthetic populations have not yet been applied to building occupant modeling but they been widely used in other fields including demography, public health and urban planning. Basic procedures are available for adjusting a sampled frequency table when the marginal tables are known [42]. An early application in micro-simulation modeling of local transportation system demand uses iterative proportional fitting to draw records from a data set in proportion to the marginal frequencies in a multi-way table of variables of interest, that is, by adjusting the covariance characteristics of a synthetic population to selected U.S. Census variables [43]. A more recent application synthesizes local population characteristics for use in an agent-based model of infectious disease epidemics [44].

Three main synthesis procedures are used: deterministic reweighting, conditional probability (Monte Carlo simulation) and combinatorial optimization (simulated annealing), with the last preferred if data and computing resources allow [45]. Deterministic re-weighting is computationally quickest and requires less setup, but along with the more computation-intensive conditional probability approach it is sensitive to the specification of constraint order and limited in the number of constraints applied; whereas simulated annealing (very computation-intensive) is not [45]. Simple versions of the conditional probability approach, such as sampling with replacement, suffer when there is missing data, but for multiple imputation of missing data, fully conditional specification (FCS) and multivariate normal imputation (MVNI) methods perform adequately $[46,47]$. An implementation in $\mathbf{R}$, used in the current paper, relies on classification and regression trees (CART) to generate synthetic populations [48]. 


\subsection{Data and Methods}

\section{$\underline{2.1 \text { Combining three data sets }}$}

This section introduces three data sets of occupant behavior in commercial buildings that individually have complementary strengths and weaknesses, and that may have different properties when combined. These data form the basis for generating a synthetic sample of building occupants. They include a recent "cross-sectional" data set, a recent "longitudinal" data set, and the larger-scale ASHRAE RP-884 data set. The longitudinal data set is described in detail elsewhere [36] and it consists of twicedaily surveys conducted in 2012 and 2013 of 24 occupants of a single office building in Philadelphia for two-week periods in four seasons of one year, accompanied by more frequent observations of indoor and outdoor temperatures and other environmental factors. The much larger ASHRAE RP-884 data set has also been well described previously [11] and it includes 20,215 occupant-specific data points spread across 160 buildings worldwide in a mix of cross-sectional and longitudinal data recorded during 1982 to 1997.

The more recent cross-sectional data set draws on a variety of small-N studies of occupant behavior in office buildings conducted by the authors between 2009 and 2014. The studies investigate a variety of questions including the range and frequency of adaptive responses, underlying reasons for particular behaviors, and selected physiological, psychological, social, and organizational factors that might influence comfort perceptions and adaptive behaviors. These studies were not designed beforehand for data pooling but it has proved to be feasible based on comparable parameters and some common protocols. The studies that contribute to the cross-sectional pooled data set are from surveys, interviews, and observations of 16 commercial buildings located in or near Philadelphia, PA, in ASHRAE Climate Zone 4A (Mixed Humid), including a total of 954 occupants, most performing office work [38, 39]. The supplemental material provides details on covariance characteristics of the data [49]. 
The process of pooling multiple data sets (longitudinal, cross-sectional, and the larger-scale ASHRAE RP884) is to: (a) locate the data and code books for each study; (b) identify studies that include, at minimum, objective measurements of outside air temperature, indoor air temperature, thermal sensation perceptions, and frequency of a set of adaptive behaviors such as adjusting a thermostat or using a local space heater; (c) develop an equivalence basis to convert the various data coding schemes to a common scheme, and carry out the data transformations; (d) pool the data; (e) perform imputation of missing values to the extent it is reasonable to do so; (f) investigate bivariate and multivariate relationships in the underlying data sets; (g) replicate these investigations using the combined data set; and $(h)$ characterize how robust the evidence is for specific bivariate and multivariate relationships in the combined data set.

Although created for different purposes, the three data sets share several variables in common as summarized in Figure 1. Definitions of the variables are shown in Table 1. Descriptive statistics for a selection of the shared variables are summarized in Table 2.

[Figure 1 Overlapping data fields in cross-sectional, longitudinal and ASHRAE RP-884 data sets about here]

[Table 1 Definitions of variables in occupant behavior data sets about here]

[Table 2 Descriptive statistics for selected shared variables in cross-sectional, longitudinal and ASHRAE RP-884 data sets]

The three data sets document different occupants, buildings, locations, and dates, but they show some consistent patterns. Among the variables summarized in Figure 1 and Table 2 (on a partial basis), the three data sets have statistically identical means for availability of portable space heaters and several other variables not shown to save space including availability of portable fans and the frequency of operation of portable fans. The means differ significantly for occupant age, occupant sex, daily average 
outdoor air temperature, and other variables not shown including daily average outdoor relative humidity, indoor air temperature, satisfaction with thermal conditions, availability of operable windows, and the frequency of operation of windows, interior doors, thermostats, and portable space heaters.

The combined data set inherits characteristics of the three underlying data sets in proportion to the number of observations in each. Thus the ASHRAE RP-884 data dominate the combined data set, and the small, cross-sectional data set is least influential. Table 2 confirms that the descriptive statistics of the combined data set are most similar to the ASHRAE RP-884 data set, which has older occupants, more naturally ventilated buildings, and warmer outdoor temperatures than in the smaller, more recent data sets.

\subsection{Creating the synthetic population}

This research employs the statistical software $\mathbf{R}$ to develop synthetic versions of the original data sets, The $\mathbf{R}$ code and results for this are given in the Appendix. The rows in Table 2 that are labeled "Synthetic" show summary statistics by variable.

\subsection{Comparing covariance structures}

We illustrate key aspects of the covariance structure within each data set by showing how well common explanatory variables predict an occupant behavior of interest in a series of logistic regression models. Logistic regression is an appropriate choice because the dependent variable is binary-whether an occupant has acquired a portable space heater $(1=\mathrm{Yes}, 0=\mathrm{No})$. Acquisition of a portable space heater is an interesting occupant behavior because it is maladaptive-it can impose a large energy consumption burden on a building.

\subsection{Results}


The mean of each variable shown in Table 2 is statistically identical at the $95 \%$ confidence level in the Synthetic and Combined Observed data sets based on paired t-tests. Figure 2 compares the frequency distributions for key variables in the observed (combined) and synthetic data sets to provide visual confirmation that the synthetic data set successfully replicates the observed data.

Table 3 shows regression models for the underlying observed data sets, the combined observed data set, and the synthetic data set. These models predict whether occupants have acquired portable space heaters. Explanatory variables include average outdoor air temperature, average indoor air temperature, occupant age, and occupant sex. As expected, the model based on the combined data set is most similar to that based on the large ASHRAE RP-884 data set.

The Likelihood Ratio (LR) Chi-Square test $\left(\mathrm{LR} \mathrm{chi}^{2}(5)\right.$ in the table) is that at least one of the explanatory variables' regression coefficients is not equal to zero in the model. The number in the parenthesis indicates the degrees of freedom of the Chi-Square distribution used to test the LR Chi-Square statistic and is defined by the number of explanatory variables in the model. The statistic is calculated as $-2 \times($ likelihood (null model) - likelihood (fitted model)). The test Prob $>\mathrm{chi}^{2}$ is the probability of getting a LR test statistic as extreme as, or more so, than the observed under the null hypothesis, which is that all of the regression coefficients in the model are equal to zero. Finally, the Pseudo $\mathrm{R}^{2}$ statistic is McFadden's pseudo $R^{2}$ and is only suggestive of a model's explanatory power; it is not formally equivalent to the $R^{2}$ found in OLS regression. Based on these statistics, the models based on the smaller longitudinal and cross-sectional data sets lack explanatory power. The models using the ASHRAE RP-884, Combined Observed, and Synthetic data sets all have significant explanatory power.

An examination of the ability of the Combined Observed (and Synthetic) models to correctly classify the binary dependent variable shows that it correctly classified overall $83 \%$ (82\%) of observations, incorrectly predicted a space heater when none was observed (false positive) in $4 \%$ (3\%) of 
observations, and incorrectly predicted no space heater when one was actually observed (false negative) in $53 \%$ (61\%) of observations. Thus, the model systematically underestimates the presence of space heaters.

All models agree on the sign (and with the exception of the small cross-sectional data set, the significance) of outdoor air temperature and occupant age in predicting portable heater acquisition, with colder locations and younger occupants being more likely to have heaters. The combined observed data set also supports significant roles for indoor air temperature and sex, with buildings having colder indoor temperatures and female occupants being more likely to have heaters.

Table 4 shows how the same regression model formulations perform on four selected subsets of the observed and synthetic data sets: (1) a selection including only naturally ventilated buildings; (2) a selection including only mechanically cooled buildings with operable windows; (3) a selection that only includes male occupants; and (4) a selection that only includes occupants under age 40. Models using the synthetic data are very similar to those using the observed data, further building our confidence that the synthetic data set closely matches the covariance structure of the combined observed data set.

In our portable space heater acquisition example shown in Table 4, the model has more explanatory power in naturally ventilated buildings than in mechanically cooled buildings or in the overall data set which also includes mechanically cooled and mixed buildings that are presumably more centrally controllable. Outdoor air temperature also plays a greater explanatory role, and indoor air temperature and age play lesser roles in naturally ventilated buildings. When selecting by gender, the explanatory power of age increases. When selecting by age, the explanatory power of gender does not change much. Table 4 thus illustrates how a synthetic population can be tailored to expected occupant and context profiles during prospective modeling supporting a design process.

\subsection{Discussion}


The previous section demonstrates the process of combining several data sets and then generating synthetic data. The descriptive statistics and modeling illustrate how well the process works, as well as the limitations of the process.

The combined observed data set has a covariance structure that echoes many of the patterns found in the underlying sources. Those original observed data sets draw on different enough locations, buildings, and people so that full decomposability is not expected, that is, the three original and the combined data sets are unlikely to exhibit identical covariance structures. Table 3 illustrates this finding, showing models built from each of the four data sets to predict a key adaptive action taken by occupants to local thermal comfort conditions. They differ from one another.

The underlying data sets each have strengths and weaknesses. The longitudinal data set provides a strong basis for exploring multivariate relationships, albeit within a narrow band defined by a single building and location, for 24 occupants. The cross-sectional data set proves to be too thin to support much multivariate analysis on thermal comfort adaptations. It draws on a larger number of respondents and buildings than the longitudinal data set but is more valuable for enumerating the range of conditions and occupant responses than for precisely characterizing the most common occupant behaviors. The larger ASHRAE RP-884 data set much more robustly supports multivariate analysis, although it is not perfectly targeted to the occupant behavior topic.

The combined data confirm several expected relationships along the causal chain from environmental condition, to environmental perceptions, to adaptive actions to improve thermal conditions (and lighting conditions, not discussed here). The data possess face validity because they demonstrate relationships previously identified in the literature. Similarly, relationships between thermal conditions and adaptive actions manifest mostly as expected. The mediating role on occupant behavior of 
contextual factors including natural ventilation and outdoor air temperature is clear, as adaptive thermal comfort model proponents previously showed using the ASHRAE RP-884 data [11].

Multivariate analysis is feasible with the combined data set. For example, the data support expected relationships between outdoor air temperature, indoor air temperature, age, sex, and the acquisition of local space heaters by occupants, as summarized by the models in Table 3. It is unable to characterize expected organizational influences on individual access to space heaters [50]. The combined data set is adequate for seed development of a synthetic population of building occupants that can be used by practitioners but it will be even more useful if it incorporates more data from other research groups. The synthetic data set supports multivariate relationships among dependent and explanatory variables that are very similar to those observed in the underlying combined data set.

A well-calibrated synthetic data set represents a more highly transferable form of occupant behavior information than (1) standard distributions, (2) building performance models calibrated to occupied existing buildings, and (3) building performance models linked in co-simulations to occupant behavior models calibrated to existing occupied buildings. It incorporates contextual information by supporting multivariate modeling of explanatory and dependent variables. It is flexible because it can support a variety of modeling approaches.

\section{$\underline{5.0 \text { Conclusions and Recommendations }}$}

This paper focuses on methodology development to help set the scope for future work in assembling combined occupant behavior data sets and generating synthetic populations. Our data sets and $\mathbf{R}$ code are available at [49]. The creation of highly polished, large- $\mathrm{N}$ synthetic populations suitable for immediate use by building modeling practitioners will have immense practical value.

However, assembling disparate data sets into a combined data set to provide an empirical basis for synthesis involves significant challenges. Although we demonstrate the feasibility of assembling a useful 
combined data set from existing field studies, we leave for future work a conclusive demonstration of the transferability of the data and its value in modeling. We further acknowledge that we have shown only one way to represent the different underlying data sets in the synthetic population, by giving each occupant observation equal weight.

Building designers would benefit if researchers develop a common core data collection protocol that individual research groups willingly implement with rigor. Researchers will be helpful if they focus on the subset of occupant behavior topics that are most relevant to simulation modeling that informs the design process in a fit-for-purpose manner, and also those behaviors for which there is currently little data. Examples include adaptive responses to thermal and lighting comfort conditions and how they vary systematically by context and the occupant's personal attributes.

Transforming a combined data set into a synthetic occupant population for use by design practitioners is additionally valuable because it eliminates the risk that specific building occupants could be identified and thereby avoids potential research ethics concerns. Alternatives procedures for synthesizing data sets need to be compared in applications to occupant behavior data to identify those that are superior.

Synthetic data sets necessarily tie their content to specific modeling approaches, hence it is important to be able to generate tailored synthetic data to meet the needs of each modeling tradition. The emerging practice of linking separate occupant behavior and building performance simulation models in a cosimulation framework will particularly benefit from such data. For example, it could serve as an input to an occupant behavior co-simulation module such as that described in [34] and it could interface with an industry-standard tool provided with a co-simulation interface such as one now under development in [37]. The general structure of the framework in [37] includes space records, occupant records, behavior records, and schedule records. Each occupant has a name, age, gender, lifestyle, job type, and list of behaviors. Behaviors include occupant movements that are scheduled within space, plus a variety of 
adaptive responses to environmental conditions. The synthetic data described in the current paper match some of the available data fields, including location, occupant characteristics, and schedule. The synthetic population by necessity will not include location or schedule data because it is meant to be usable for studying occupant behavior in hypothetical buildings during the design process. Therefore any associated modeling framework will need to assign occupants to locations and schedules.

Finally, it is important to remember that many aspects of design practice are best served by identifying central tendencies and standard distributions of occupant behavior variables. Synthetic populations of building occupants are a useful tool for some but not all aspects of building performance modeling practice.

\section{$\underline{\text { References }}$}

[1] Bordass, B., Leaman, A. and Ruyssevelt, P. 2001. Assessing building performance in use 5: conclusions and implications. Building Research \& Information 29(2): 144-157.

[2] Larsen, T. S., Knudsen, H. N., Kanstrup, A. M., Christiansen, E. T., Gram-Hanssen, K., Mosgaard, M., Rose, J. 2010. Occupants Influence on the Energy Consumption of Danish Domestic Buildings: state of the art. Aalborg: Department of Civil Engineering, Aalborg University. (DCE Technical Reports; No. 110).

[3] Haas, R. Auer, H., and Biermayr, P. The impact of consumer behavior on residential energy demand for space heating. Energy and Buildings, 27, 195-205, 1998.

[4] Leaman, A. and Bordass, B. Productivity in buildings: the "killer" variables, Building Research \& Information 27(1), 4-20, 1999.

[5] International Energy Agency (IEA). 2013. Final Report IEA Annex 53 - total energy use in buildings, analysis and evaluation methods: Occupant behavior and modeling. Separate document, vol. II. IEA.

[6] Hewitt, E., Andrews, C., Senick, J. Wener, R., Krogmann, U. and Sorensen Allacci, M. 2015. Distinguishing between green building occupants' reasoned and unplanned behaviors. Building Research and Information. Advance online publication. doi: 10.1080/09613218.2015.1015854.

[7] Gaetani, I., Hoes, P-J., and Hensen, J.L.M. 2016. Occupant behavior in building energy simulation: Towards a fit-for-purpose modeling strategy. Energy and Buildings 121, 188-204. http://dx.doi.org/10.1016/j.enbuild.2016.03.038.

[8] ASHRAE (American Society of Heating Refrigeration and Air-conditioning Engineers). 2013. 2013 ASHRAE Handbook: Fundamentals, ch. 9 on thermal comfort. Atlanta, GA: ASHRAE, esp. pg. 9.25 . 
[9] ANSI/ASHRAE Standard 55-2013: Thermal Environmental Conditions for Human Occupancy. Atlanta, GA. ISSN 1041-2336.

[10] Fanger, P.O. 1972. Thermal Comfort: Analysis and Applications in Environmental Engineering. New York: McGraw-Hill.

[11] de Dear, R.J., and G.S. Brager, 1998. Towards an adaptive model of thermal comfort and preference. ASHRAE Transactions, Vol 104 (1), pp. 145-167.

[12] ASHRAE (American Society of Heating Refrigeration and Air-conditioning Engineers). 1989. 1989 ASHRAE Handbook: Fundamentals, ch. 8 on physiological principles, comfort, and health. Atlanta, GA: ASHRAE.

[13] Crawley, D.B., Hand, J.W., Kummert, M., Griffith, B.T., 2008. Contrasting the capabilities of building energy performance simulation programs. Building and Environment 43, 661-673.

[14] ANSI/ASHRAE/IES Standard 90.1-2013: Energy Standard for Buildings Except Low-Rise Residential Buildings, Appendix G: Performance Rating Method, pp. 254-270. Atlanta, GA: ASHRAE. ISSN 1041-2336.

[15] Waltz, J. P. 1999. Computerized Building Energy Simulation Handbook. Prentice Hall Professional Technical Reference: Upper Saddle River, NJ, ISBN-13: 9780130859129.

[16] Reddy, T.A., Maor, I., Jian, S., Panjapornporn, C., 2006. Procedures for reconciling computercalculated results with measured energy data. ASHRAE Research Project 1051-RP.

[17] Hubler, D., Tupper, K., Greensfelder, E., 2010. Pulling the Levers on Existing Buildings: A Simple Method for Calibrating Hourly Energy Models. ASHRAE Transactions 116, 261-268.

[18] Monfet, D., Zmeureanu, R., Charneux, R., Lemire, N., 2009. Calibration of a Building Energy Model Using Measured Data. ASHRAE Transactions 115, 348.

[19] Raftery, P., Keane, M., Costa, A., 2009. Calibration of a detailed simulation model to energy monitoring system data: a methodology and case study, in: Eleventh International IBPSA Conference.

[20] Song, S., Haberl, J.S., 2008a. SL-08-037-A Procedure for the Performance Evaluation of a New Commercial Building: Part 1-Calibrated As-Built Simulation. ASHRAE Transactions 114, 375.

[21] Song, S., Haberl, J.S., 2008b. SL-08-038-A Procedure for the Performance Evaluation of a New Commercial Building: Part II-Overall Methodology and Comparison of Methods. ASHRAE Transactions 114, 389.

[22] Yoon, J., Lee, E.J., Claridge, D.E., 2003. Calibration procedure for energy performance simulation of a commercial building. Journal of Solar Energy Engineering 125, 251-257.

[23] Burch, J., Subbarao, K., Lekov, A., Warren, M., Norford, L., 1990. Short-term energy monitoring in a large commercial building. ASHRAE Transactions 96, 1459-1477.

[24] Carroll, W.L., Hitchcock, R.J., 1993. Tuning simulated building descriptions to match actual utility data: methods and implementation. ASHRAE Transactions-American Society of Heating Refrigerating Air Conditioning Engineers 99, 928-934. 
[25] Norford, L.K., Socolow, R.H., Hsieh, E.S., Spadaro, G.V., 1994. Two-to-one discrepancy between measured and predicted performance of a "low-energy" office building: insights from a reconciliation based on the DOE-2 model. Energy and Buildings 21, 121-131.

[26] Pan, Y., Huang, Z., Wu, G., 2007. Calibrated building energy simulation and its application in a high-rise commercial building in Shanghai. Energy and Buildings 39, 651-657.

[27] Ajzen, I. "The theory of planned behavior," Org. Behav. Human Decis. Process., vol. 50, no. 2, pp. 179-211, Dec. 1991.

[28] Stern, P.C. "Toward a coherent theory of environmentally significant behavior," J. Social Issues, vol. 56, no. 3, pp. 407-424, 2000.

[29] Rao, A.S., and M. P. Georgeff, "Decision procedures for BDI logics," J. Logic Comput., vol. 8, no. 3, pp. 293-342, Jun. 1998.

[30] Norling, E., E. Sonenberg, and R. Ronnquist, "Enhancing multi-agent-based simulation with humanlike decision-making strategies," in Proc. 2nd Int. Workshop MABS, vol. 1979. Boston, MA: Springer-Verlag, 2000, pp. 214-228.

[31] Jennings, N.R. "On agent-based software engineering," Artif. Intell., vol. 117, no. 2, pp. 277-296, Mar. 2000.

[32] Haldi, F., and Robinson, D. On the behaviour and adaptation of office occupants. Building and Environment 43 (2008): 2163-2177.

[33] Widén, J., Nilsson, A.M., and Wäckelgård, E. 2009. A combined Markov-chain and bottom-up approach to modelling of domestic lighting demand. Energy and Buildings 41 (2009): 1001-1012.

[34] Andrews, C.J., Yi, D., Krogmann, U., Senick, J., and Wener, R. 2011. Designing buildings for real occupants: An agent-based approach. IEEE Transactions on Systems Man and Cybernetics A: Systems and Humans 41(6) (November 2011): 1077-1091.

[35] Stoppel, C.M., and Leite, F. 2014. Integrating probabilistic methods for describing occupant presence with building energy simulation models. Energy and Buildings 68 (2014): 99-107.

[36] Langevin, J., J Wen, PL Gurian. 2015. Simulating the human-building interaction: Development and validation of an agent-based model of office occupant behaviors. Building and Environment 88 (June): 27-45. doi:10.1016/j.buildenv.2014.11.037.

[37] Hong, Tianzhen, Hongsan Sun, Yixing Chen, Sarah C. Taylor-Lange, Da Yan. 2015a. An occupant behavior modeling tool for co-simulation. Energy and Buildings (in press).

doi:10.1016/j.enbuild.2015.10.033.

[38] Andrews, C.J., H. Chandra Putra, and C. Brennan. "Simulation Modeling of Occupant Behavior in Commercial Buildings". Prepared by the Center for Green Building at Rutgers University for the Energy Efficient Buildings Hub, Philadelphia, PA. 2013. At http://rcgb.rutgers.edu/wpcontent/uploads/2013/09/EEBHub_ModelingReport_2013.pdf

[39] Malenchak, S., Sorensen Allacci, M., and Andrews, C.J. 2014. Preliminary experimental evaluations of occupant behavior during load shedding. Prepared by the Center for Green Building at Rutgers University for the Energy Efficient Buildings Hub, Philadelphia, PA. http://rcgb.rutgers.edu/wp-content/uploads/2014/05/LoadSheddingReport20140131.pdf. 
[40] Lenzuni, P., D. Freda \& M. del Gaudio. 2009. Classification of Thermal Environments for Comfort Assessment. Ann. Occup. Hyg., Vol. 53, No. 4, pp. 325-332.

[41] Drechsler, Jörg, Bender, Stefan, and Rässler, Susanne. 2008. Comparing Fully and Partially Synthetic Datasets for Statistical Disclosure Control in the German IAB Establishment Panel. Transactions on Data Privacy 1 (2008): 105-130.

[42] Deming W. E. and Stephan F. F. 1940. On a least squares adjustment of a sampled frequency table when the expected marginal tables are known. Annals Math/Stats 11: 427-444.

[43] Beckman, R.J., K.A. Baggerly and M.D. McKay. 1996. Creating synthetic baseline populations. Transportation Research A 30(6): 415-429.

[44] Wheaton, W.D., Cajka, J.C., Chasteen, B.M., Wagener, D.K., Cooley, P.C., Ganapathi, L., Roberts, D.J., and Allpress, J.L. 2009. Synthesized Population Databases: A US Geospatial Database for Agent-Based Models. Methods Rep RTI Press. doi:10.3768/rtipress.2009.mr.0010.0905.

[45] Harland, K., Heppendstall, A., Smith, D., and Birkin, M. 2012. Creating Realistic Synthetic Populations at Varying Spatial Scales: A Comparative Critique of Population Synthesis Techniques. Journal of Artificial Societies and Social Simulation 15(1):1. http://jasss.soc.surrey.ac.uk/15/1/1.html.

[46] Lee, K.L., and Carlin, J.B. 2010. Multiple Imputation for Missing Data: Fully Conditional Specification Versus Multivariate Normal Imputation. American Journal of Epidemiology 171(5):624-632. DOI: 10.1093/aje/kwp425.

[47] Frazier, T., and Alfons, A. 2012. Generating a Close-to-Reality Synthetic Population of Ghana. SSRN Electronic Journal 01/2012; DOI: 10.2139/ssrn.2086345

[48] Nowok, B., G. M. Raab, and C. Dibben (2015). synthpop: Bespoke creation of synthetic data in R. Package vignette http://cran.r-project.org/web/packages/synthpop/vignettes/synthpop.pdf. Accessed: 2015-11-22.

[49] Underlying and synthetic data sets, and $\mathbf{R}$ code are available at greenbuilding.rutgers.edu.

[50] Barr, S., Shaw, G., and Coles, T. (2011). Sustainable lifestyles: Sites, practices, and policy. Environment and Planning A, 43: 3011-3029. DOI: 10.1068/a43529. 
Appendix: $\mathbf{R}$ code for generating synthetic data

To generate synthetic data sets we use an add-on package to $\mathbf{R}$ introduced in [48], synthpop

via

$$
\text { R> library ("synthpop") }
$$

Before synthesizing the original data set by calling the function syn(), we need to load the file containing the data set into a data frame. The data set also needs to be clarified and recoded before being ready for analysis. The missing data code in the data set is recoded to R's missing data code "NA." To make the process reproducible, an additional parameter seed is used. The resulting object of class synds is here called sdata, where sobdata stands for "synthesized occupant behavior dataset". The parameter m indicating the number of synthesis instances is set to 5 in order to generate several versions of the synthetic data that are then averaged, and other arguments are left as defaults. The parameter drop.not.used is set to FALSE (otherwise the method and predictor.matrix will miss information on variables that are excluded from the model). By default, all variables except for the first one in the visit sequence (visit.sequence) are synthesized using the ctree implementation of CART models that can handle any type of data. The first variable is a random sample with replacement drawn from its observed values. The $\mathbf{R}$ code for this is given below.

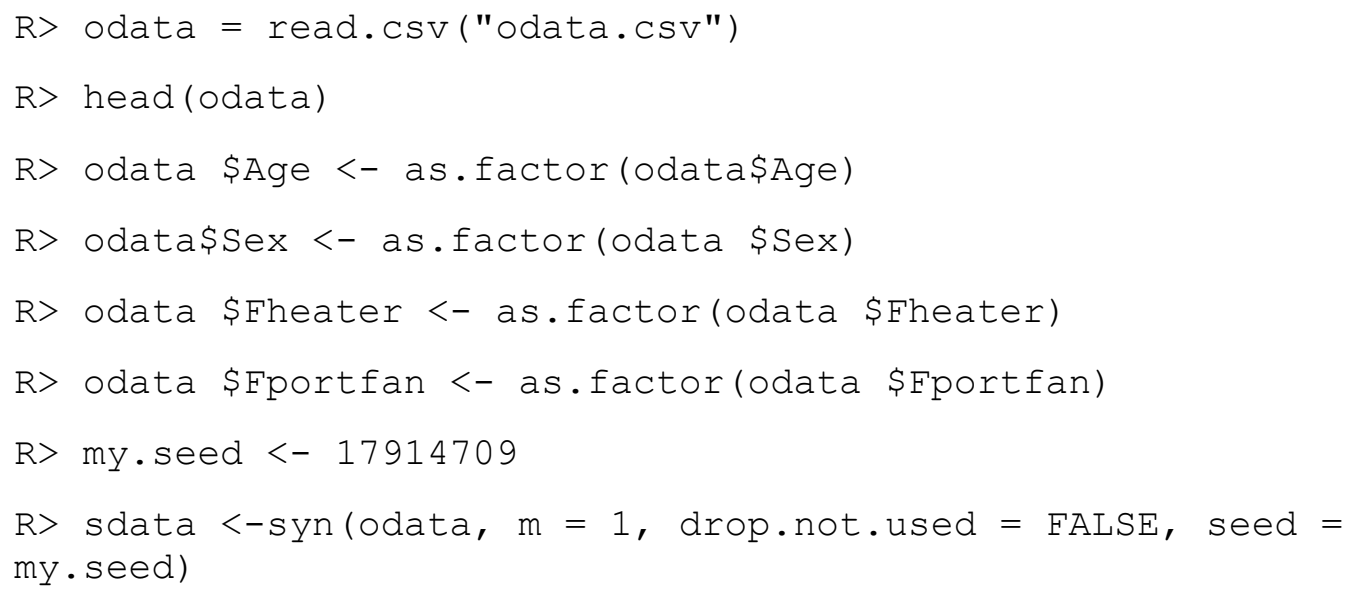




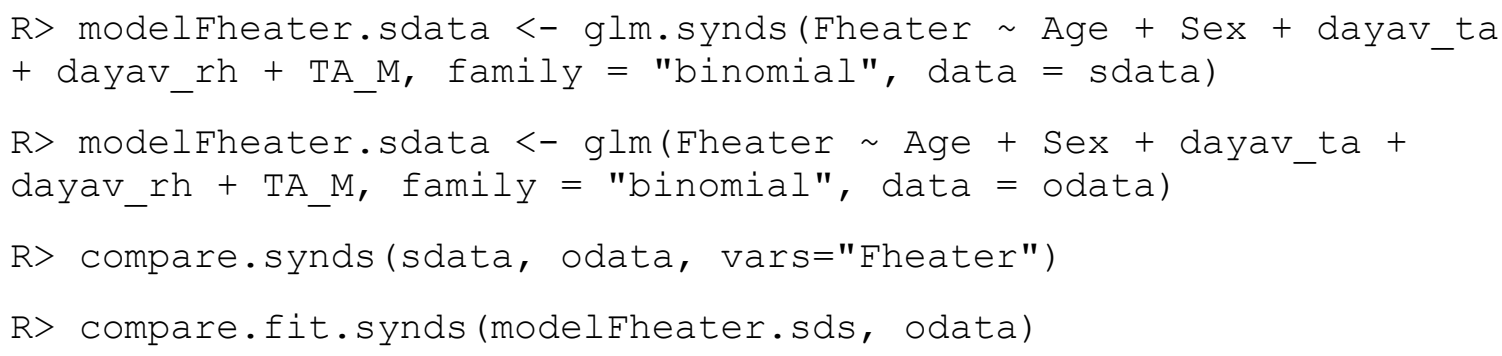

A synthpop function, compare.synds(), provides an easy way to compare the synthesized variables with the original ones. It takes arguments of a synthetic data object and a data frame with original data and compares relative frequency distributions of each variable in tabular and graphic form. It can also be used for a subset of variables specified by a vars argument. We estimate the original data model using generalized linear model implemented in $\mathbf{R} \mathbf{g l m}()$ function. A function glm.synds() of the synthpop package estimates models for each of the $\mathbf{m}$ synthesized data sets. Function compare.fit.synds(), used in the code, allows the comparison of the estimates based on the synthesized data sets and those based on the original data. 
Table 1: Definitions of variables in occupant behavior data sets

\begin{tabular}{|c|c|}
\hline Variable & Definition \\
\hline Age & $1=0-19,2=20-29,3=30-39,4=40-49,5=50-59,6=60-69,7=70-79$ \\
\hline Sex & 1=male, $2=$ female \\
\hline dayav_ta & outdoor average air temperature on day of survey, C \\
\hline TA_M & indoor air temperature at $0.6 \mathrm{~m}$ above floor, $\mathrm{C}$ \\
\hline Hheater & respondent's access to portable space heater, $1=$ has access, $0=$ doesn't have access \\
\hline \multirow[t]{2}{*}{ Ventcat } & 1=Mixed, 2=HVAC, 3=Natural ventilation \\
\hline & The following variables are not shown in subsequent tables \& charts to save space: \\
\hline dayav_rh & outdoor average relative humidity on day of survey, $\%$ \\
\hline HOpWin & respondent's access to operable windows, $1=$ has access, $0=$ doesn't have access \\
\hline HInDoors & respondent's access to interior doors, $1=$ has access, $0=$ doesn't have access \\
\hline Htstat & respondent's access to thermostat, $1=$ has access, $0=$ doesn't have access \\
\hline Hblinds & respondent's access to window blinds, $1=$ has access, $0=$ doesn't have access \\
\hline Hportfan & respondent's access to portable fan, $1=$ has access, $0=$ doesn't have access \\
\hline FOpWin & $\begin{array}{l}\text { how often respondent adjusts windows, } 1=\text { na, } 2=\text { never, } 3=\text { rarely, } 4=\text { sometimes, } 5=\text { often, } \\
6=\text { always }\end{array}$ \\
\hline FInDoors & $\begin{array}{l}\text { how often respondent adjusts interior doors, } 1=\text { na, } 2=\text { never, } 3=\text { rarely, } 4=\text { sometimes, } \\
5=\text { often, } 6=\text { always }\end{array}$ \\
\hline Ftstat & $\begin{array}{l}\text { how often respondent adjusts thermostat, } 1=\text { na, } 2=\text { never, } 3=\text { rarely, } 4=\text { sometimes, } 5=0 \text { ften, } \\
6=\text { always }\end{array}$ \\
\hline Fblinds & $\begin{array}{l}\text { how often respondent adjusts window blinds, } 1=\text { na, } 2=\text { never, } 3=\text { rarely, } 4=\text { sometimes, } \\
5=\text { often, } 6=\text { always }\end{array}$ \\
\hline Fportfan & $\begin{array}{l}\text { how often respondent adjusts portable fan, } 1=\text { na, } 2=\text { never, } 3=\text { rarely, } 4=\text { sometimes, } 5=\text { often, } \\
6=\text { always }\end{array}$ \\
\hline Fheater & $\begin{array}{l}\text { how often respondent adjusts portable space heater, } 1=\text { na, } 2=\text { never, } 3=\text { rarely, } 4=\text { sometimes, } \\
5=\text { often, } 6=\text { always }\end{array}$ \\
\hline SATEMP & respondent's satisfaction with workspace temperature, 1=low to 7=high \\
\hline Source & 1=Longitudinal data set, $2=$ Cross-sectional data set, 3=ASHRAE RP-884 data set \\
\hline
\end{tabular}


Table 2: Descriptive statistics of selected shared variables in cross-sectional, longitudinal, and ASHRAE RP-884 observed data sets and the synthetic data set

\begin{tabular}{|c|c|c|c|c|c|c|}
\hline Variable & Source & Mean & Standard Deviation & Minimum & Maximum & $\mathrm{N}$ \\
\hline \multirow[t]{5}{*}{ Age } & Longitudinal & 4.13 & 1.30 & 2.00 & 6.00 & 2408 \\
\hline & Cross-sectional & 3.93 & 1.32 & 1.00 & 7.00 & 748 \\
\hline & ASHRAE RP-884 & 2.50 & 1.31 & 1.00 & 7.00 & 18834 \\
\hline & Combined & 2.72 & 1.42 & 1.00 & 7.00 & 21990 \\
\hline & Synthetic & 2.73 & 1.42 & 1.00 & 7.00 & 22004 \\
\hline \multirow[t]{5}{*}{ Sex } & Longitudinal & 1.64 & 0.48 & 1.00 & 2.00 & 2497 \\
\hline & Cross-sectional & 1.43 & 0.50 & 1.00 & 2.00 & 791 \\
\hline & ASHRAE RP-884 & 1.50 & 0.50 & 1.00 & 2.00 & 24212 \\
\hline & Combined & 1.51 & 0.50 & 1.00 & 2.00 & 27500 \\
\hline & Synthetic & 1.51 & 0.50 & 1.00 & 2.00 & 27465 \\
\hline \multirow[t]{5}{*}{ Dayav_ta } & Longitudinal & 14.85 & 10.47 & -5.00 & 33.00 & 2497 \\
\hline & Cross-sectional & 16.94 & 5.16 & 1.56 & 26.50 & 955 \\
\hline & ASHRAE RP-884 & 18.93 & 9.92 & -24.90 & 35.00 & 24847 \\
\hline & Combined & 18.50 & 9.92 & -24.90 & 35.00 & 28299 \\
\hline & Synthetic & 18.48 & 9.89 & -24.90 & 35.00 & 28262 \\
\hline \multirow[t]{5}{*}{ TA_M } & Longitudinal & 23.21 & 1.46 & 16.39 & 27.75 & 2480 \\
\hline & Cross-sectional & 24.15 & 0.71 & 21.00 & 25.89 & 600 \\
\hline & ASHRAE RP-884 & 22.07 & 8.36 & 0.00 & 42.67 & 24734 \\
\hline & Combined & 22.22 & 7.91 & 0.00 & 42.67 & 27814 \\
\hline & Synthetic & 22.21 & 7.92 & 0.00 & 42.50 & 27804 \\
\hline \multirow[t]{5}{*}{ Hheater } & Longitudinal & 0.22 & 0.42 & 0.00 & 1.00 & 2269 \\
\hline & Cross-sectional & 0.26 & 0.44 & 0.00 & 1.00 & 307 \\
\hline & ASHRAE RP-884 & 0.24 & 0.43 & 0.00 & 1.00 & 11544 \\
\hline & Combined & 0.24 & 0.43 & 0.00 & 1.00 & 14120 \\
\hline & Synthetic & 0.24 & 0.43 & 0.00 & 1.00 & 13855 \\
\hline \multirow[t]{5}{*}{ Ventcat } & Longitudinal & 1.00 & 0.00 & 1.00 & 1.00 & 2497 \\
\hline & Cross-sectional & 1.97 & 0.35 & 1.00 & 3.00 & 955 \\
\hline & ASHRAE RP-884 & 2.45 & 0.54 & 1.00 & 3.00 & 25124 \\
\hline & Combined & 2.30 & 0.66 & 1.00 & 3.00 & 28576 \\
\hline & Synthetic & 2.30 & 0.66 & 1.00 & 3.00 & 28576 \\
\hline
\end{tabular}


Table 3: Logistic Regression Models for Underlying Observed Data Sets and Synthetic Data Set

\begin{tabular}{|c|c|c|c|c|c|}
\hline Data Set & $\begin{array}{l}\text { Longitudinal } \\
\text { Observed }\end{array}$ & $\begin{array}{l}\text { Cross- } \\
\text { sectional } \\
\text { Observed }\end{array}$ & $\begin{array}{l}\text { ASHRAE RP- } \\
884 \\
\text { Observed }\end{array}$ & $\begin{array}{l}\text { Combined } \\
\text { Observed }\end{array}$ & Synthetic \\
\hline $\begin{array}{l}\text { Dependent } \\
\text { Variable }\end{array}$ & Hheater & & & & \\
\hline $\begin{array}{l}\text { Explanatory } \\
\text { Variables }\end{array}$ & $\begin{array}{l}\text { Coefficient } \\
\text { (Std Dev) }\end{array}$ & & & & \\
\hline dayav_ta & $\begin{array}{l}-0.017^{* *} \\
(0.006) \\
\end{array}$ & $\begin{array}{l}-0.052 \\
(0.047) \\
\end{array}$ & $\begin{array}{l}-0.026 * * * \\
(0.003) \\
\end{array}$ & $\begin{array}{l}-0.012 * * * \\
(0.003) \\
\end{array}$ & $\begin{array}{l}-0.015 * * * \\
(0.003) \\
\end{array}$ \\
\hline TA_M & $\begin{array}{l}0.201 * * * \\
(0.047) \\
\end{array}$ & $\begin{array}{l}-0.056 \\
(0.231) \\
\end{array}$ & $\begin{array}{l}-0.361 * * * \\
(.011) \\
\end{array}$ & $\begin{array}{l}-0.338 * * * \\
(0.009) \\
\end{array}$ & $\begin{array}{l}-0.321 * * * \\
(0.009) \\
\end{array}$ \\
\hline Age & $\begin{array}{l}-0.318 * * * \\
(0.048)\end{array}$ & $\begin{array}{l}-0.005 \\
(0.136) \\
\end{array}$ & $\begin{array}{l}-0.111 * * * \\
(0.026) \\
\end{array}$ & $\begin{array}{l}-0.130 * * * \\
(0.020) \\
\end{array}$ & $\begin{array}{l}-0.080 * * * \\
(0.021) \\
\end{array}$ \\
\hline Sex & 0 (omitted) & $\begin{array}{l}-0.863^{*} \\
(0.369) \\
\end{array}$ & $\begin{array}{l}0.518 * * * \\
(0.062) \\
\end{array}$ & $\begin{array}{l}0.837 * * * \\
(0.055) \\
\end{array}$ & $\begin{array}{l}0.710 * * * \\
(0.055) \\
\end{array}$ \\
\hline Constant & $\begin{array}{l}-3.740 * * \\
(1.088)\end{array}$ & $\begin{array}{l}2.960 \\
(5.72)\end{array}$ & $\begin{array}{l}7.156^{* * *} \\
(0.258)\end{array}$ & $\begin{array}{l}5.930 * * * \\
(0.219)\end{array}$ & $\begin{array}{l}5.670 * * * \\
(0.210)\end{array}$ \\
\hline $\begin{array}{l}\text { Number of } \\
\text { obs }\end{array}$ & 1,495 & 147 & 8,674 & 10,894 & 10,878 \\
\hline $\operatorname{LR} \operatorname{chi}^{2}(5)$ & 70 & 7 & 3,231 & 3,162 & 2,823 \\
\hline Prob > chi ${ }^{2}$ & $0.000 * * *$ & 0.14 & $0.000 * * *$ & $0.000 * * *$ & $0.000 * * *$ \\
\hline Pseudo $\mathrm{R}^{2}$ & 0.04 & 0.04 & 0.32 & 0.25 & 0.23 \\
\hline
\end{tabular}

Note: Asterisks show which variables are significant at the 0.1 level $(*), 0.01$ level $(* *)$, and 0.001 level $(* * *)$. 
Table 4: Logistic Regression Models for Selected Subsets within Original and Synthetic Data Sets for Dependent Variable Hheater

\begin{tabular}{|c|c|c|c|c|c|c|c|c|}
\hline Selection & $\begin{array}{l}\text { Naturally } \\
\text { ventilated } \\
\text { buildings }\end{array}$ & & $\begin{array}{l}\text { Mechanically } \\
\text { ventilated } \\
\text { buildings with } \\
\text { operable } \\
\text { windows }\end{array}$ & & $\begin{array}{l}\text { Male } \\
\text { occupants }\end{array}$ & & $\begin{array}{l}\text { Occupant } \\
\text { age }<40\end{array}$ & \\
\hline Data Set & $\begin{array}{l}\text { Observed } \\
\text { (Combined) }\end{array}$ & Synthetic & $\begin{array}{l}\text { Observed } \\
\text { (Combined) }\end{array}$ & Synthetic & $\begin{array}{l}\text { Observed } \\
\text { (Combined) }\end{array}$ & Synthetic & $\begin{array}{l}\text { Observed } \\
\text { (Combined) }\end{array}$ & Synthetic \\
\hline $\begin{array}{l}\text { Explanatory } \\
\text { Variables }\end{array}$ & $\begin{array}{l}\text { Coefficient } \\
\text { (Std Dev) }\end{array}$ & & & & & & & \\
\hline dayav_ta & $\begin{array}{c}-0.204^{* * *} \\
(0.012)\end{array}$ & $\begin{array}{c}-0.184 * * * \\
(0.011)\end{array}$ & $\begin{array}{c}-0.016 * * \\
(0.006)\end{array}$ & $\begin{array}{l}-0.002 \\
(0.006)\end{array}$ & $\begin{array}{c}-0.015^{* *} \\
(0.005)\end{array}$ & $\begin{array}{c}-0.010 * * * \\
(0.005)\end{array}$ & $\begin{array}{c}-0.018 * * * \\
(0.004)\end{array}$ & $\begin{array}{c}-0.014 * * \\
(0.004)\end{array}$ \\
\hline TA_M & $\begin{array}{c}-0.159 * * * \\
(0.014)\end{array}$ & $\begin{array}{c}-0.178 * * * \\
(0.014)\end{array}$ & $\begin{array}{c}0.200 * * * \\
(0.046)\end{array}$ & $\begin{array}{c}0.031 \\
(0.042)\end{array}$ & $\begin{array}{c}-0.279 * * * \\
(0.013)\end{array}$ & $\begin{array}{c}-0.269 * * * \\
(0.013)\end{array}$ & $\begin{array}{c}-0.325 * * * \\
(0.012)\end{array}$ & $\begin{array}{c}-0.324 * * * \\
(0.012)\end{array}$ \\
\hline Age & $\begin{array}{c}-0.357 * * * \\
(0.039)\end{array}$ & $\begin{array}{c}-0.222 * * * \\
(0.037)\end{array}$ & $\begin{array}{c}-0.291 * * * \\
(0.046)\end{array}$ & $\begin{array}{c}-0.337^{* * *} \\
(0.046)\end{array}$ & $\begin{array}{c}-0.387^{* * *} \\
(0.039)\end{array}$ & $\begin{array}{c}-0.369 * * * \\
(0.039)\end{array}$ & $\begin{array}{c}-0.260 * * * \\
(0.054)\end{array}$ & $\begin{array}{c}-0.231^{* * *} \\
(0.054)\end{array}$ \\
\hline Sex & $\begin{array}{c}0.878^{* * *} \\
(0.091)\end{array}$ & $\begin{array}{c}0.629 \\
(0.089)\end{array}$ & $\begin{array}{c}5.087^{* * *} \\
(0.585)\end{array}$ & $\begin{array}{c}5.110^{* * *} \\
(0.585)\end{array}$ & $\begin{array}{c}0 \\
\text { (omitted) }\end{array}$ & $\begin{array}{c}0 \\
\text { (omitted) }\end{array}$ & $\begin{array}{c}0.666^{* * *} \\
(0.071)\end{array}$ & $\begin{array}{c}0.512 * * * \\
(0.072)\end{array}$ \\
\hline Constant & $\begin{array}{c}6.600 * * * \\
(0.281)\end{array}$ & $\begin{array}{c}6.690 * * * \\
(0.272)\end{array}$ & $\begin{array}{c}-14.008 * * * \\
(1.574)\end{array}$ & $\begin{array}{c}-10.23^{* * *} \\
(1.50)\end{array}$ & $\begin{array}{c}6.220 * * * \\
(0.305)\end{array}$ & $\begin{array}{c}5.890 * * * \\
(0.277)\end{array}$ & $\begin{array}{c}6.250 * * * \\
(0.279)\end{array}$ & $\begin{array}{c}6.280 * * * \\
(0.268)\end{array}$ \\
\hline Number of obs & 5,086 & 4,949 & 2,201 & 2,256 & 4,785 & 4,710 & 6,334 & 6,297 \\
\hline LR chi2(5) & 3,191 & 3,037 & 474 & 458 & 991 & 1,093 & 2,082 & 1,986 \\
\hline Prob > chi2 & $0.000 * * *$ & $0.000 * * *$ & $0.000 * * *$ & $0.000 * * *$ & $0.000 * * *$ & $0.000 * * *$ & $0.000 * * *$ & $0.000 * * *$ \\
\hline Pseudo R2 & 0.47 & 0.46 & 0.19 & 0.19 & 0.21 & 0.22 & 0.29 & 0.28 \\
\hline
\end{tabular}

Note: Asterisks show which variables are significant at the 0.1 level $\left({ }^{*}\right), 0.01$ level $\left({ }^{* *}\right)$, and 0.001 level $\left({ }^{* *}\right)$. 
Figure 1: Overlapping data fields in cross-sectional, longitudinal and ASHRAE RP-884 data sets

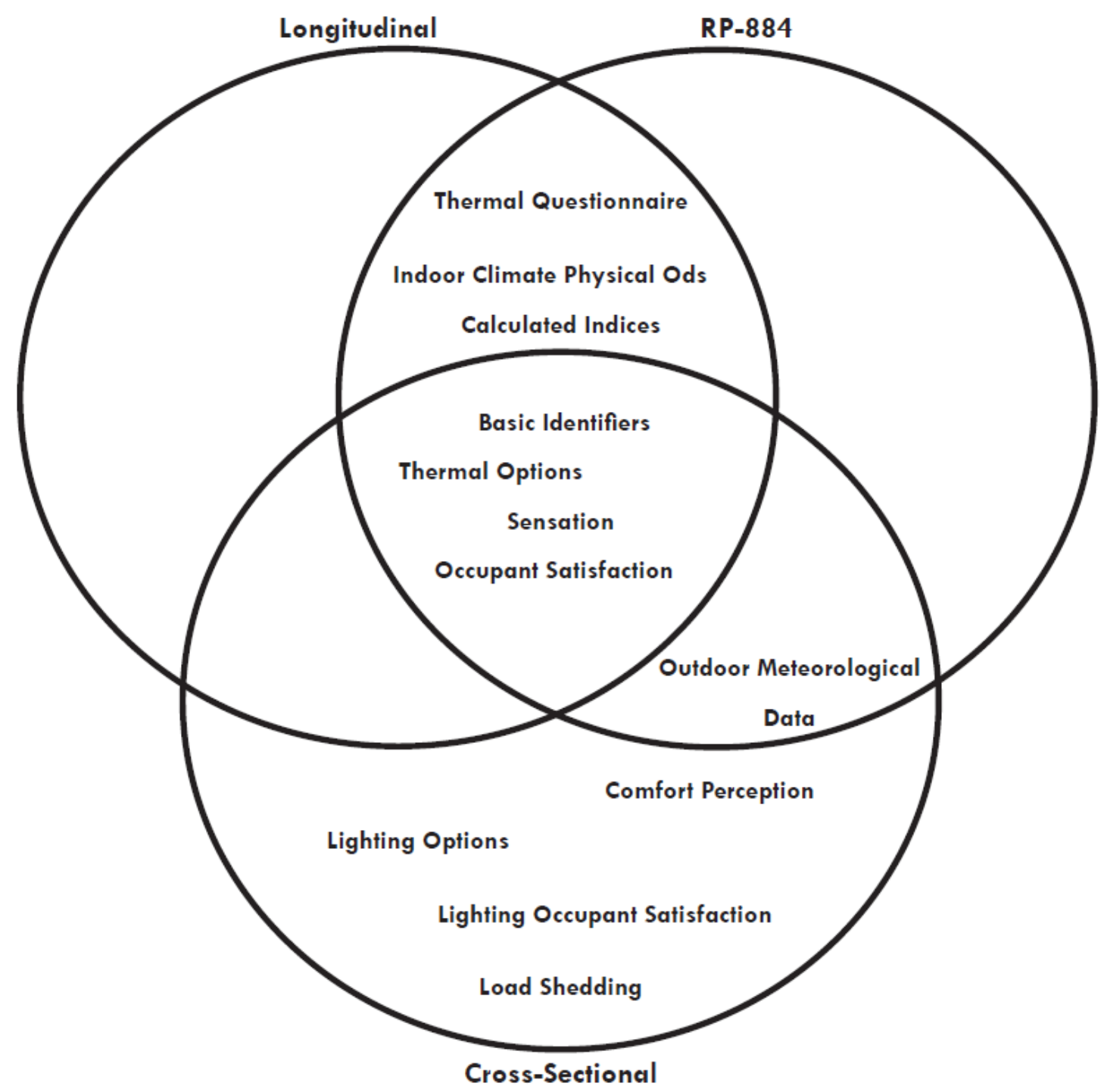


Figure 2: Comparison of frequency distributions for key variables in observed and synthetic data sets

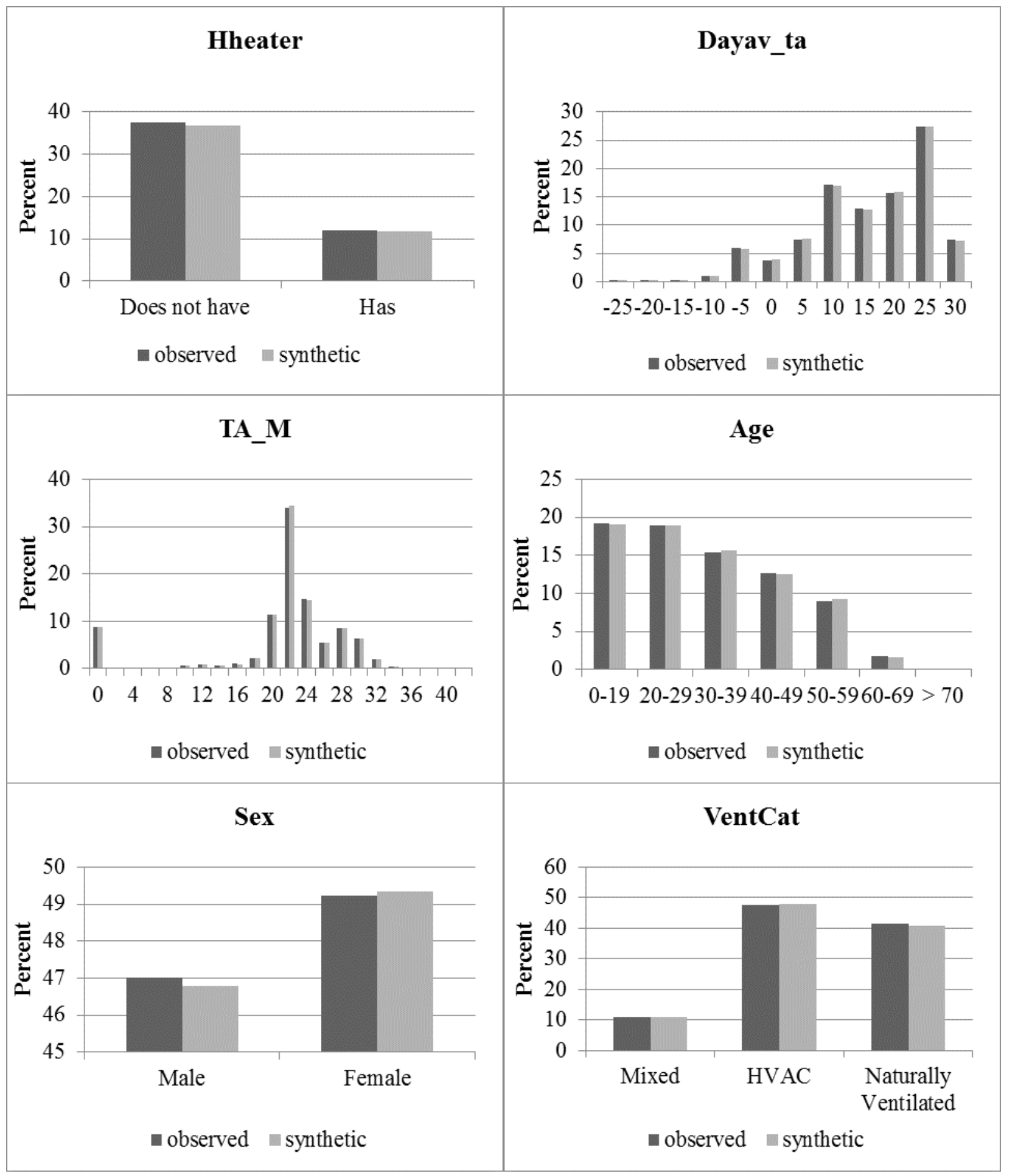

